\title{
CULTURA POLÍtTICA PÓS-CONSENSO DE WASHINGTON: O CONCEITO DE CULTURA CÍVICA E A MUDANÇA POLÍTICA NA AMÉRICA LATINA
}

\author{
Henrique Carlos de Oliveira de Castro \\ Daniel Capistrano
}

\begin{abstract}
Resumo
O artigo propõe uma reflexão crítica do conceito de cultura cívica e sua aplicação em estudos sobre mudança política na América Latina. O índice pós-materialista, um exemplo de uso desse conceito, foi testado como uma variável explicativa da cultura política em países europeus e latino-americanos. A análise dos dados da Pesquisa Mundial de Valores aponta para necessidade de se rever a operacionalização de variáveis nos estudos sobre cultura política na América Latina.
\end{abstract}

Palavras-Chave: Cultura Política; Cultura Cívica; América Latina; Pósmaterialismo; Mudança Política.

\begin{abstract}
The article proposes a critical reflection on the concept of civic culture and its use in the study of political change in Latin America. The post-materialism index, an example of the use of this concept was tested as an explanatory variable of the political culture in European and Latin American countries. Data analysis of the World Values Survey points to the need of reviewing the operationalization of variables in studies of political culture in Latin America.
\end{abstract}

Key-Words: Political Culture; Civic Culture; Latin America; Post-materialism; Political Change.

\section{Introdução}

Mesmo após quatro décadas de publicação do trabalho clássico de Gabriel Almond e Sidney Verba (1965), os debates em torno do conceito de "cultura política" não terminaram. Em decorrência da forte associação ainda recorrente com a idéia de "cultura cívica", os diversos trabalhos dessa área, principalmente os estudos empíricos, carecem de melhor distinção entre os conceitos de "cultura política" e "cultura cívica".

Essa situação pode ser observada em trabalhos aplicados à realidade latino-americana que, além de confundir esses conceitos, utilizam a operacionalização elaborada para estudos em regiões como a Europa e a América do Norte como modelos, sem o devido 
reconhecimento de que tal apropriação merece um questionamento quanto a possibilidade de aplicação a outras realidades históricas, econômicas, sociais e culturais.

Mais recentemente, esse problema pode ser encontrado nos estudos de transição em que são atribuídos diversos fatores da cultura política como importantes para a mudança ou manutenção de um determinado regime político (MOISÉS, 1995).

O resgate da história desses conceitos é um importante passo para a análise dessa situação. Com a publicação, na década de 1960 nos Estados Unidos, do livro The Civic Culture: political attitudes and democracy in five countries, de Gabriel Almond e Sidney Verba (1965), o conceito de Cultura Política se tornou famoso dentro da Ciência Política e gerou um grande impacto na maneira de se estudar este tema até então.

Embora a idéia de cultura política fosse empregada desde o século XVIII, somente com esta obra pioneira de Almond e Verba o conceito passou a ser trabalhado de maneira sistemática. Dentre as razões para esse começo tardio dos estudos de cultura política, afirma Almond (1980), estão o avanço na metodologia estatística e das ciências sociais - como o survey - que proporcionaram novas possibilidades, inexistentes ou precárias até então, de estudos focados no indivíduo e o desenvolvimento das teorias sociais dos séculos XIX e XX que concorreram para o embasamento da cultura política na década de 1960. A tradição sociológica de Max Weber, Talcott Parsons e outros, a psicologia social de Lippman, Wallas e Lazarsfeld; bem como a contribuição de cientistas sociais como Ruth Benedict, Margaret Mead e Harold Lasswell, são componentes explícitos da fundamentação teórica do conceito.

No entanto, a obra de Almond e Verba é mais do que uma decorrência do trabalho desses teóricos aliada ao emprego de novas metodologias de pesquisa. Além da inovação na maneira de se enxergar os fenômenos políticos, este trabalho também é fruto e reflexo de um contexto político e social muito peculiar.

REVISTA DEBATES, Porto Alegre, v. 2, n.1, p. 75-97, jan.-jun.2008. 
É importante notar que o conceito de cultura cívica - que dá origem à discussão de cultura política - é elaborado em uma época marcada pelo choque da humanidade frente às conseqüências dos regimes autoritários e da II Guerra Mundial, e em um país que, vitorioso, assumia aos poucos sua posição hegemônica de modelo político para o mundo. Portanto, se torna importante uma apreciação mais detalhada deste contexto para se compreender a presença do ambiente sócio-econômico e político na obra de Almond e Verba.

Uma das características mais marcantes desta influência é o desvio da explicação, por meio do conceito de cultura política, para a proposição de uma relação entre "cultura cívica" e democracia. Apesar de ser a primeira vez em que o conceito de cultura política é aplicado, os principais argumentos presentes na obra giram em torno da cultura cívica. A principal idéia defendida é a de que a cultura cívica, como uma forma específica de cultura política, seria a mais propensa ao surgimento e ao desenvolvimento estável de regimes democráticos. Para demonstrar isto, Almond e Verba realizam um estudo em cinco países, identificando tipos específicos de cultura política que seriam combinações distintas de três "tipos puros": cultura paroquial, cultura súdita e cultura participativa. A primeira seria caracterizada por uma estrutura de valores tradicionais, descentralizada, em que os indivíduos estão reduzidos à esfera particular. A cultura súdita é caracterizada por uma estrutura autoritária, marcada pela centralização, idealizada como um meio termo entre a completa ausência do indivíduo em relação ao sistema político, na cultura paroquial, e o sentimento de completa inclusão na esfera pública, característico da cultura participativa. No estudo publicado, o arranjo mais adequado ao surgimento e à manutenção estável de um regime democrático está na combinação denominada Cultura Cívica, cujos representantes empíricos mais próximos seriam os Estados Unidos e o Reino Unido.

Portanto, a consagração do conceito de cultura política com a publicação da obra de Almond e Verba foi marcada, também, pelo forte apelo ao aspecto normativo. Após a publicação de The Civic Culture, diversos autores passaram a adotar a cultura política como um 
referencial teórico e metodológico para o estudo de fenômenos políticos. No entanto, este crescimento do campo, também foi acompanhado por uma forte onda de críticas. Como afirma Castro:

\begin{abstract}
A principal e mais séria crítica diz respeito aos pressupostos da obra The Civic Culture, ou seja, a postulação de um determinado tipo de cultura política como requisito necessário e absoluto para a constituição e consolidação da democracia, no caso, a cultura cívica existente nos Estados Unidos e na GrãBretanha (2000, p.39).
\end{abstract}

Resultante desta postulação, numerosas críticas se concentraram no caráter etnocêntrico do estudo em questão, e acabaram por desqualificar o trabalho como um todo. Embora o estudo tenha centrado suas atenções sobre a defesa de uma determinada cultura como a mais apropriada ao regime democrático, a proposta de se estudar as atitudes e orientações individuais como parte relevante do arcabouço de explicação dos fenômenos políticos foi o grande mérito da obra de Almond e Verba.

Apesar de seguidas críticas - em geral, críticas à cultura cívica terem acompanhado o desenvolvimento dos estudos de cultura política na década de 1960, uma série de autores levou a frente esta proposta de maneiras distintas.

A questão da mudança, por exemplo, desde os primeiros desenvolvimentos teóricos é um desafio para os estudos de cultura política. Grande parte das críticas a este referencial teórico metodológico se concentra no fato de ser esta uma área inadequada para abordar de forma satisfatória a mudança política. Para Eckstein (2000, p. 307), "Existe uma boa razão para isto: as suposições da abordagem da cultura política, de fato, levam à expectativa de continuidade". Herança de trabalhos inspiradores como os de Max Weber e Talcott Parsons, esta ênfase na continuidade e a dificuldade de se tratar a mudança política foram características marcantes da formação do conceito de cultura política.

Por ser tomada como uma das esferas mais insuscetíveis à mudança, a cultura política tem sido adotada como um arcabouço de explicação voltado, principalmente, para a continuidade. Como afirma 
Rennó (1997, p. 262), "O argumento principal dos estudos sobre o tema é de que apesar dos grandes esforços de indotrinação e manipulação por parte dos regimes, poucas mudanças ocorreram na cultura desses países". Em parte, este é um dos principais trunfos desta corrente, pois a noção de que cultura política é uma variável autônoma em relação às estruturas políticas e econômicas, resgata a importância de se considerar esta variável como um fator decisivo.

Contudo, alguns esforços dentro desta corrente teóricometodológica têm se concentrado sobre a mudança na cultura política. Rennó também assinala que

\begin{abstract}
Por outro lado, a mudança nos valores culturais sobre política implica no estudo das causas dessa mudança, o que permite avaliar as variáveis associadas à formação da cultura política. Permite, portanto analisar a influência da estrutura política na cultura política, confirmando a postura almondiana de considerar essa relação extremamente complexa (1997, p. 262).
\end{abstract}

Não somente a estrutura política, mas as estruturas social, econômica e cultural são influentes no processo de mudança. A grande questão, portanto, reside sobre os principais fatores que acarretam a mudança. Muitos autores defendem a existência de causas e processos de transformação mais ou menos semelhantes em todos os países. No entanto, esta concepção tem encontrado muitas dificuldades, tanto no seu embasamento teórico quanto na sua aplicação em casos empíricos.

Em sua análise sobre a diferença entre a Alemanha Ocidental de 1959, participante do survey de Almond e Verba analisado em The Civic Culture, e a Alemanha Ocidental do final dos anos de 1970, David Conradt (1980) verifica algumas alterações na cultura política desse país. Embora estivesse comprometido com o deslocamento da cultura política alemã "em direção" à cultura cívica, Conradt pauta sua argumentação por meio de quatro processos básicos que dão origem às mudanças em uma dada cultura política:

A maioria dos analistas [acadêmicos]... estudam mudança política na Alemanha pós-guerra] tem focado as seguintes fontes de mudança: (1) socialização pósguerra, particularmente como evidenciada pelos efeitos da variável idade; (2) a ausência de alguma alternativa confiável (crível) à democracia liberal; 
modernização sócio-econômica do pós-guerra; e (4) desempenho do sistema (1980, p.256).

Além disso, destaca um ponto essencial à discussão que se segue no presente trabalho de que "Até hoje, nenhum modelo compreensivo de mudança, que especifique o peso relativo e a inter-relação entre esses fatores, surgiu" (CONRADT, 1980, p.256).

Quando modelos compreensivos como este sugerido surgem, costumam subvalorizar especificidades políticas, econômicas e históricas. Esquemas de causalidade em estudos sobre mudança na cultura política tendem a enfatizar modelos generalistas dados ou a criar novos mecanismos que sejam aplicáveis a outras situações.

Corroborando este ponto de vista, Craig e Cornellius (1980), em uma revisão semelhante à de David Conradt, ressaltam a necessidade, no caso mexicano, de se considerar, como fatores importantes, suas propriedades particulares. Craig e Cornellius, após o estudo chegam à seguinte conclusão:

Finalmente, futuros pesquisadores de "temas transnacionais", apreciando a inclusão do México em seus estudos, podem tomar consciência dos aspectos autoritários do sistema político mexicano. Poderia se argumentar que o sistema mexicano pode ser comparado, de forma mais produtiva, com outros regimes 'autoritários' ou 'autoritário-corporatistas' na América Latina, Sul da Europa, ou os sistemas democráticos estáveis Afro-asiáticos (1980, p. 382383).

Pode-se afirmar, também, que mais frutífera ainda é a análise, tanto individual quanto em perspectiva comparada, de casos que possuam raízes histórico-sociais semelhantes e que estejam inseridos em contextos sociais, econômicos e culturais similares.

\section{Cultura cívica e pós-materialismo}

Embora um esforço muito grande tenha sido empenhado para interpretar as mudanças políticas, econômicas e sociais ocorridas nestas últimas décadas, pouco autores têm trabalhado a influência destas mudanças sobre a dinâmica da cultura política. 
Dentre estes, Ronald Inglehart é o autor mais conhecido por se aprofundar na questão da mudança cultural. A forte relação entre economia e bem estar social, por exemplo, é uma situação verificada por Inglehart em muitas ocasiões. No entanto, este é somente o ponto de partida de seu trabalho.

Em 1971, o artigo The Silent Revolution in Europe: Intergenerational Change in Post-Industrial Societies é publicado na American Political Science Review e inaugura a atual discussão sobre o pós-materialismo. Neste texto, Inglehart faz a primeira defesa de sua tese sobre a mudança intergeracional de valores nas sociedades industriais avançadas. Basicamente, verifica o surgimento de uma sociedade predominantemente pós-materialista, baseada em valores como participação, qualidade de vida e auto-expressão, enquanto valores materialistas, como segurança física e econômica, enfraquecem nas gerações mais recentes. Esta transformação nos sistemas de valores básicos estaria se dando em decorrência de algumas modificações no nível do sistema.

A forma de mensurar esta mudança se deu, inicialmente, por meio da seguinte questão, formulada aos respondentes:

Se você tivesse que escolher entre as seguintes coisas, quais seriam as duas que pareceriam mais desejáveis para você:

Manter a ordem no país;

Dar ao povo mais voz nas decisões políticas importantes;

Combater o aumento dos preços;

Proteger a liberdade de expressão (INGLEHART, 1971, p.994). 
Figura 1 - Esquema hipotético de "The Culture Shift"

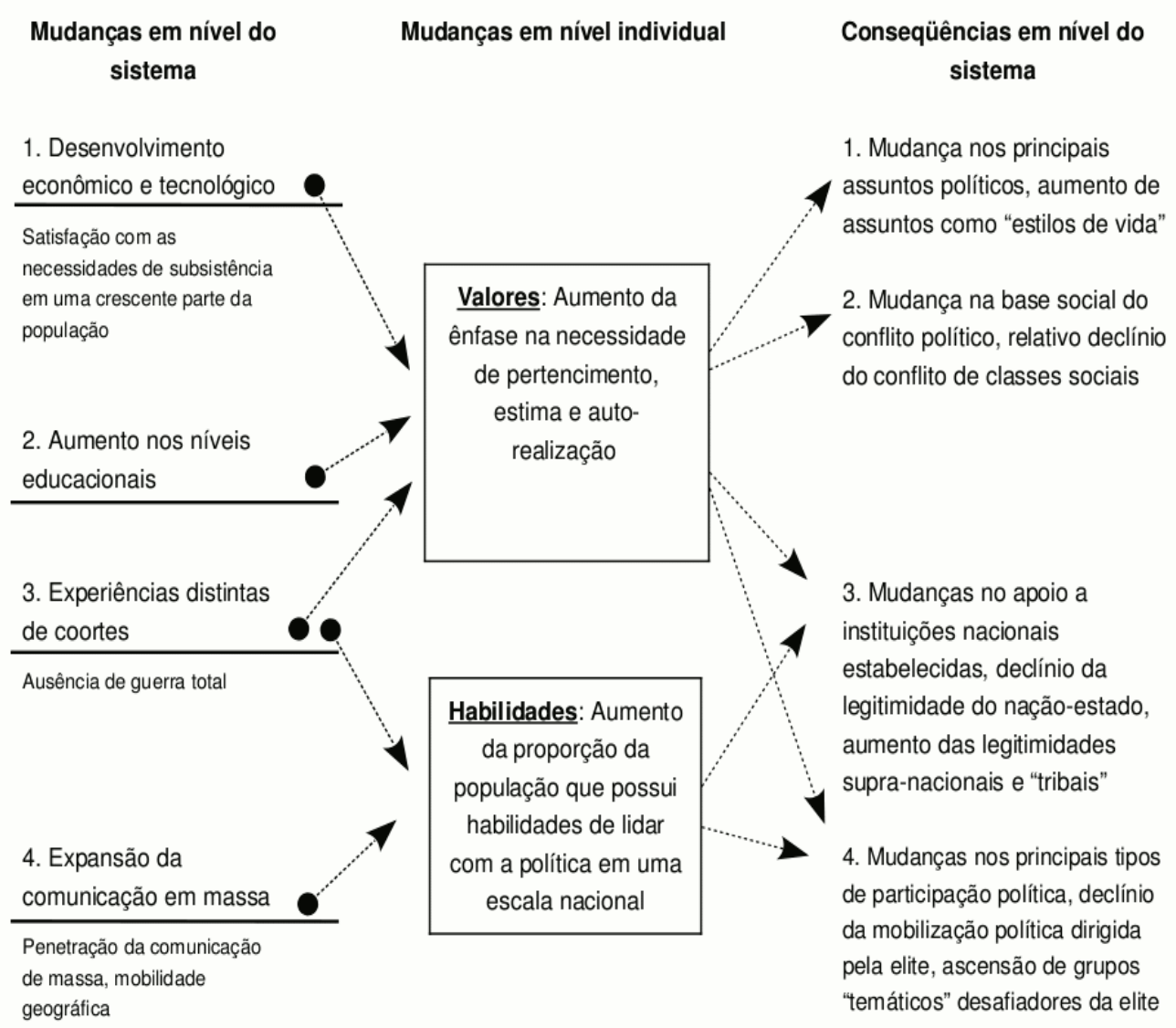

Fonte: Adaptado de INGLEHART $(1990$, p.6).

De acordo com a hipótese de Inglehart, das seis respostas possíveis a seleção do par "manter a ordem no país" e "combater o aumento de preços" indicariam que o respondente teria uma posição mais ligada a valores "aquisitivos". A seleção do outro par de respostas indicaria uma postura mais ligada a valores pós-burgueses. Esta mudança inter-geracional, levaria Inglehart (apud McLARNEY e CHUNG, 1999) a afirmar, seis anos depois que "Os valores de públicos ocidentais têm mudado de uma esmagadora ênfase no bem-estar material e segurança física para maior ênfase na qualidade de vida...".

Em trabalhos posteriores, Inglehart passou a adotar termos diferentes, mas que conservaram os mesmos conceitos. Os valores "aquisitivos" passaram a ser chamados de valores "materialistas" e os 
valores "pós-burgueses" passaram a ser chamados de valores "pósmaterialistas".

Poucas modificações substanciais foram impostas à forma de se mensurar o pós-materialismo de lá para cá. Uma década depois, questionários mais elaborados foram aplicados em mais países da Europa no European Values Survey (EVS) ${ }^{1}$ e até 2006, com a aplicação da quinta onda do World Values Survey(WVS) ${ }^{2}$, esta questão permanece idêntica. Novos itens foram incluídos para a criação de um índice mais sofisticado de pós-materialismo. Além dos 4 itens da questão citada anteriormente, outros 8 itens relacionados à preferência do entrevistado foram adicionados ao questionário para mensurar o pós-materialismo, a saber: manter altas taxas de crescimento econômico; assegurar que o país tenha importantes forças de defesa; dar maior importância à opinião das pessoas sobre os assuntos em seu trabalho e comunidade; tornar cidades e paisagens mais bonitas; manter a economia estável; progredir em direção a uma sociedade menos impessoal e mais humana; lutar contra a delinqüência; progredir em direção a uma sociedade onde as idéias são mais importantes do que o dinheiro.

Como já foi dito, a medida de pós-materialismo está ligada a uma questão específica sobre a opinião dos entrevistados em relação à economia e à segurança física. Baseado em um estudo de caso realizado na Alemanha, Markus Klein (apud HANSEN e TOL, 2003) critica a forma unidimensional de mensuração da mudança de valores, pois esta se daria de fato de maneira difusa sem uma direção específica como expressaria a tese pós-materialista. Em resposta às críticas em relação ao caráter unidimensional, Inglehart (1998, p.162) tece algumas considerações e afirma ser esta a dimensão predominante em um universo de diversas alterações nas orientações de valores modernos e pós-modernos.

1 O European Values Survey (EVS) é uma pesquisa social sobre os valores básicos realizada em cerca de 25 países europeus.

${ }^{2}$ A Pesquisa Mundial de Valores (WVS da sigla em inglês de World Values Survey) é uma investigação mundial sobre mudanças socioculturais e políticas. É conduzida por uma rede de cientistas sociais ligados a importantes universidades em todo o mundo. São feitas entrevistas com amostras representativas da população de mais de 80 sociedades em seis continentes. Esta pesquisa já foi realizada cinco vezes desde 1981. 
Clarke et al. (1999), juntamente com Davis e Davenport (1999) apresentam posições semelhantes em artigos publicados em uma edição da American Political Science Review. Para eles, a influência nas respostas em relação à questão sobre o pós-materialismo é dada, sobretudo, por aspectos econômicos.

Para Clarke e seus colegas (1999), o índice de pós-materialismo é muito influenciado pela questão do desemprego. Os entrevistados preocupados com o seu desemprego seriam forçados a escolher questões das quais mais se preocupavam e, por isso, haveria uma tendência a classificá-los como típicos materialistas. No entanto, a identificação de valores materialistas, nestes casos, seria fruto de contingências econômicas e não de mudanças mais profundas em relação à forma de pensar destes indivíduos.

De acordo com os estudos de Davis e Davenport (1999), realizados nos Estados Unidos, a tendência verificada por Inglehart de que pessoas mais ricas tendem a apresentar valores mais próximos aos pós-materialistas não está de acordo com a realidade. Para Inglehart e Baker:

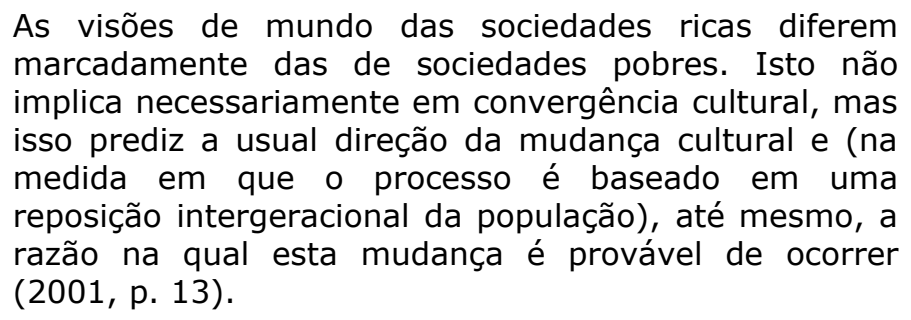

Além da associação entre nível de renda e pós-materialismo, Davis e Davenport (1999) criticam a possibilidade de previsão, baseada no índice de pós-materialismo, de atitudes em relação a assuntos políticos e sociais. Em defesa a constantes críticas em relação à dificuldade de aplicação de suas teses à realidade dos Estados Unidos, Inglehart e Baker (2001, p.20) afirmam que este país é, claramente, um "caso desviante", pois possui "muito mais valores tradicionais do que qualquer outra sociedade industrial avançada".

Em um paper disponível na Internet, Hansen e Tol (2003, p.4) trabalham os dados levantados por Inglehart em uma proposta de 
correção do índice de pós-materialismo que considera o contexto de inflação e de desemprego. Desta forma, chegam à conclusão de que existe, sim, "uma tendência genuína em direção à pós-modernidade em cada sociedade observada". No entanto, afirmam que esta tendência é bem menor do que a verificada por Inglehart (1971, 1990, 1998). Após uma análise de dados resultantes da aplicação de painéis, afirma que, apesar de questões como inflação e desemprego influenciarem os resultados do survey, uma tendência em direção ao pós-materialismo pode ser observada, mesmo em proporções menores às identificadas por Ronald Inglehart.

\section{Mudança política na América Latina}

O eixo principal da mudança em direção ao pós-materialismo está relacionado à mudança de sociedades com predomínio de processos de modernização ao predomínio de processos de pós-modernização. Para isto, Inglehart se apóia sobre o principal ponto em comum entre as duas principais teorias da Modernização - de Weber e de Marx - sobre a mudança sócio-econômica.

De forma semelhante aos trabalhos seminais de Daniel Bell (1973) e Alain Touraine (1970), Inglehart afirma que as mudanças no nível do sistema são resultados da superação de uma sociedade baseada no processo de modernização ou, como afirmam os dois autores, da sociedade industrial.

Aspectos levantados por Inglehart como importantes mudanças no nível do sistema - provimento de segurança física, altos níveis de educação - são fatores verificados, geralmente em países cujo projeto de formação de um Welfare State teve êxito. 
Figura 2 - A mudança aos Valores Pós-materialistas entre populações de nove sociedades ocidentais. (1970-1994)

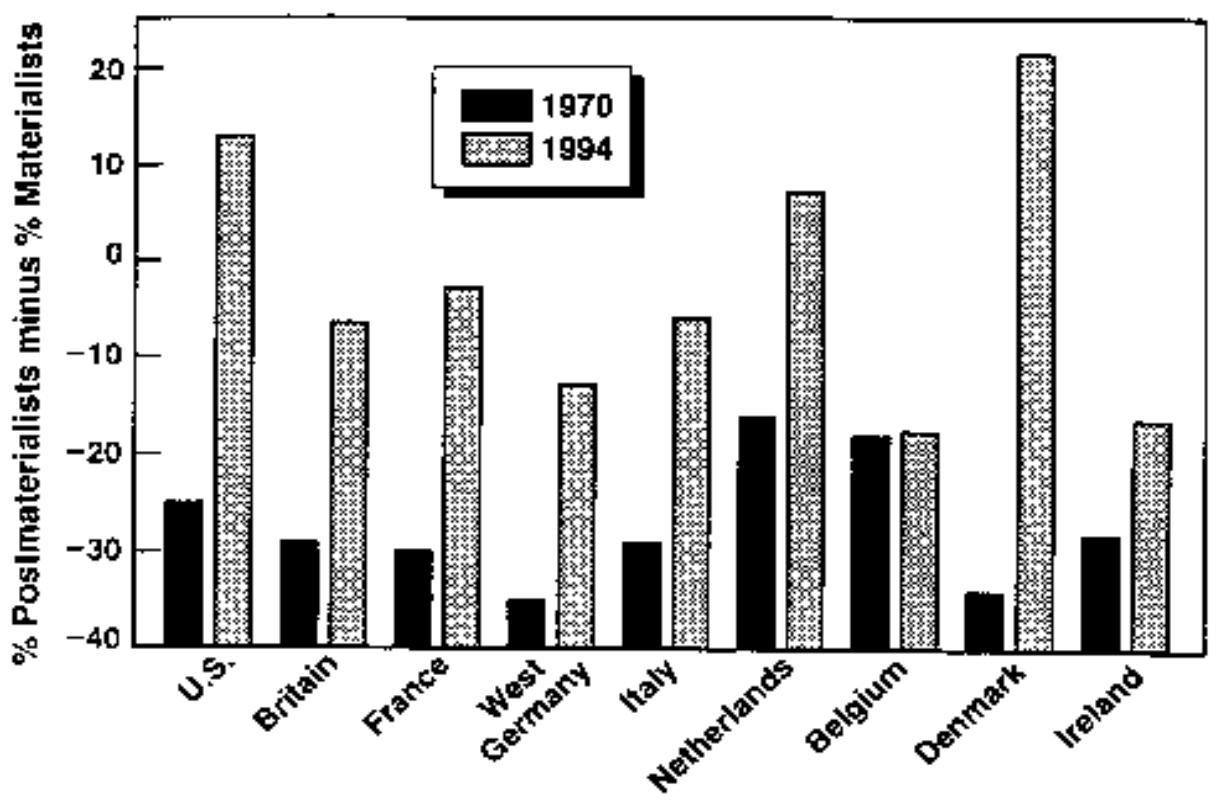

Fonte: www.worldvaluessurvey.com. Acesso em: 3 jun. 2007. European Community surveys. February,1970 and Fall,1994; and (despite the legend above) U.S. National Election Surveys from 1972 and 1992.

A proposta de se estabelecer um Estado com vistas à garantia de benefícios sociais, no entanto, esteve bem distante da consolidação do Welfare State nos países latino-americanos, por exemplo. Essa situação se torna muito mais clara ao se analisar o contexto latino-americano perante o Consenso de Washington que marcou a abertura política da maioria dos países dessa região, pautada pelo predomínio e imposição de um modelo liberal de Estado.

Após uma breve revisão das teorias sobre a institucionalização do Welfare State e sua relação com os países subdesenvolvidos, Marcelo Medeiros chega à seguinte conclusão com relação à aplicabilidade de teorias a respeito de países desenvolvidos sobre casos de países subdesenvolvidos:

A transposição das teorias sobre o desenvolvimento do Welfare State nos países desenvolvidos da América do Norte ou da Europa Ocidental para países subdesenvolvidos enfrenta alguns obstáculos, como as diferenças no contexto histórico de surgimento e desenvolvimento do Welfare State, as diferenças na velocidade de institucionalização das políticas e as 
peculiaridades culturais, políticas e socioeconômicas dos países em questão. Isso requer a redefinição de alguns conceitos [...] e adaptações nas teorias para lidar com a segmentação da sociedade em setores modernos e tradicionais e com as diferenças na cultura política, no nível de influência dos movimentos de trabalhadores e na capacidade de governo da burocracia (1999, p.16-17).

Mesmo em países que alcançaram um Estado com capacidade de garantir educação básica, segurança física e econômica para a grande maioria da população - Estados Unidos, Canadá, Austrália, Coréia do Sul -, a transformação de valores em direção ao pós-materialismo não se deu da mesma maneira como nas sociedades que possuíram Welfare State consolidados. Embora a discussão sobre o fim do Welfare State como uma decorrência da crise ocorrida na década de 1970 ainda gere polêmica, não existem dúvidas em relação ao seu impacto sobre a sociedade.

Como Seligson (2002) aponta, as mudanças ocorridas no nível do sistema identificadas por Inglehart $(1971,1990,1998)$ como as responsáveis pela criação do contexto propício ao surgimento de valores pós-materialistas, parecem estar estritamente ligadas ao contexto sóciohistórico de alguns países da Europa ocidental e do Norte americano. Isto não implica que a dimensão "materialismo - pós-materialismo" só exista nestas sociedades. No entanto, é necessário que, ao analisar as características desta dimensão em outras sociedades, se considere seu contexto social, econômico e político específico não como ambiente desta mudança, mas como agente singular de transformação.

A associação dessa tese ao conceito de cultura cívica se faz presente a partir do momento em que Inglehart identifica uma "tendência" da mudança cultural ligada a um determinado conjunto de valores identificados no processo de mudança social e político de determinados países. Ou seja, as bases da superação de uma sociedade materialista são características muito particulares de algumas sociedades estudadas por Inglehart. Para Seligson

A hipótese de Inglehart, baseada em associações do nível do sistema, é de que uma síndrome de atitudes ligadas a confiança interpessoal, satisfação de vida, e

REVISTA DEBATES, Porto Alegre, v. 2, n.1, p. 75-97, jan.-jun.2008. 
oposição a mudanças revolucionárias compreende a base para uma cultura cívica e está relacionada à democracia. No entanto, a mensuração de dados de confiança e democracia, no nível macro, não parece se adequar à maioria dos casos ao redor do mundo, exceto para um pequeno grupo de democracias avançadas altamente industrializadas do norte da Europa e da América do Norte (2002, p.287).

\section{Para um conceito de cultura política e uma análise da mudança política adequados à realidade latino-americana}

Por ter levantado questões como a mudança de valores, o pósmaterialismo, a cultura política, a democracia e, principalmente, a interrelação entre estes, a colaboração de Ronald Inglehart ultrapassou as discussões estritas sobre o tema e formou, juntamente com outras colaborações, um instrumental teórico que dá base para outras perspectivas dentro da Ciência Política.

Embora grande parte de seu trabalho pareça ter caído no que Castro (2000, p.42) chama de "armadilha da cultura cívica" ${ }^{3}$, ele representa um grande avanço em relação à proposta dos estudos iniciais de cultura política da década de 1960, pois reduz o simplismo e o caráter normativo destas primeiras noções na medida em que introduz, de maneira elaborada, a idéia de mudança na cultura política e de nãolinearidade. Ao mesmo tempo seu trabalho figura hoje como uma das principais alternativas às teorias de escolha racional, institucionalistas e economicistas da Ciência Política.

No entanto, sua teoria apresenta grandes dificuldades em lidar com situações distintas a de países como Dinamarca, Suécia, Canadá e Reino Unido. Sua proposta de tratar uma cultura política específica como um fator determinante da democracia, apesar de ser repetidamente negado em seus textos, perpassa toda a discussão de mudança de valores, cultura política e democracia:

cultura política é uma variável interveniente que ajuda a explicar porque o desenvolvimento econômico conduz, mas não necessariamente leva, à emergência

\footnotetext{
${ }^{3}$ Neste caso "a democracia e a cultura cívica seriam inerentes a dadas sociedades, como fossem fenômenos naturais, sendo impossível o processo de construção de democracia (ou de uma cultura política democrática)" (CASTRO, 2000, p. 42).
} 
de democracias modernas ou de massa (INGLEHART, 1990, p. 20).

Isto, contudo, não invalida a importância de seu trabalho, também, para a compreensão de realidades de fora da Europa e da América do Norte. Diversas possibilidades surgem com a contribuição do trabalho de Inglehart com relação ao pós-materialismo, à cultura política e à democracia.

O presente trabalho não procurou avaliar a validade interna da medida de pós-materialismo como diversos trabalhos propõem. Como Ednaldo Ribeiro (2007) procurou demonstrar, as variáveis construídas pelo WVS para mensurar o pós-materialismo possuem coerência entre si mesmo em países como o Brasil. Para esse autor

identificamos que as prioridades manifestas pelos indivíduos nas duas amostras [1991 e 1997] possuem significativa coerência interna e, ao que tudo indica, podem ser satisfatoriamente representadas por uma única dimensão que opõe tendências materialistas a pós-materialistas (RIBEIRO, 2007, p. 397).

O objeto de questionamento dessa reflexão é a utilidade dessa construção para a relação proposta entre a posição de uma sociedade no eixo "materialismo - pós-materialismo" e a efetividade de um regime democrático nessa sociedade.

$\mathrm{Na}$ maioria dos trabalhos de Inglehart, as relações são exploradas a partir de uma comparação entre médias das variáveis para cada país. Nos resultados, o grau de correlação encontrado entre a presença de valores pós-materialistas e a manutenção de um regime democrática são altos (INGLEHART, 1990, 1998).

Para testarmos essa hipótese foi utilizada uma amostra de 13 países $^{4}$ em cinco ondas do World Values Survey com o objetivo de identificar a importância do índice pós-materialista em valores e orientações políticas dos respondentes.

\footnotetext{
${ }^{4}$ Alemanha, Argentina, Brasil, Canadá, Chile, Colômbia, Estados Unidos, Finlândia, França, Holanda, México, Suécia, Suíça e Uruguai. Da base do WVS contida no arquivo "XWVSEVS_1981_2005_v20080220.sav".
} 
Utilizando a questão "opinião sobre ter um sistema político democrático" ${ }^{\prime 5}$ como variável dependente, testou-se 0 modelo de regressão ordinal $^{6}$ com 0 índice pós-materialista como variável independente. $\mathrm{Na}$ amostra da quinta onda, tanto o índice de 4 itens (Pseudo R2: "Cox and Snell" = 0,012; "Nagelkerke" $=0,014$; "McFadden" $=0,006$ ) quanto o de 12 itens (Pseudo R2: "Cox and Snell" $=0,016$; "Nagelkerke" $=0,019$; "McFadden" $=0,009)$ apresentaram um efeito de influência significativo (para $p<0,05$ ) sobre a variável dependente apesar de baixo. Quando são consideradas as amostras por países obtemos os resultados indicados pelo Gráfico 1 .

\footnotetext{
${ }^{5}$ A questão E117 contém o seguinte enunciado: "Vou descrever alguns tipos de sistemas políticos e gostaria de saber o que o(a) $\mathrm{Sr}$ (a) pensa sobre cada um deles como modo de governar o País. Para cada um, diga se é ótimo, bom, ruim ou péssimo?" As respostas foram recodificadas para "ótimo $=4$ ", "bom=3", "ruim=2" e "péssimo=1".

${ }^{6}$ O modelo testa se os efeitos da variável independente são os mesmos para todos os níveis da variável dependente (ordinal).
} 
Gráfico 1 - Regressão Ordinal (Coeficiente Cox and Snell)

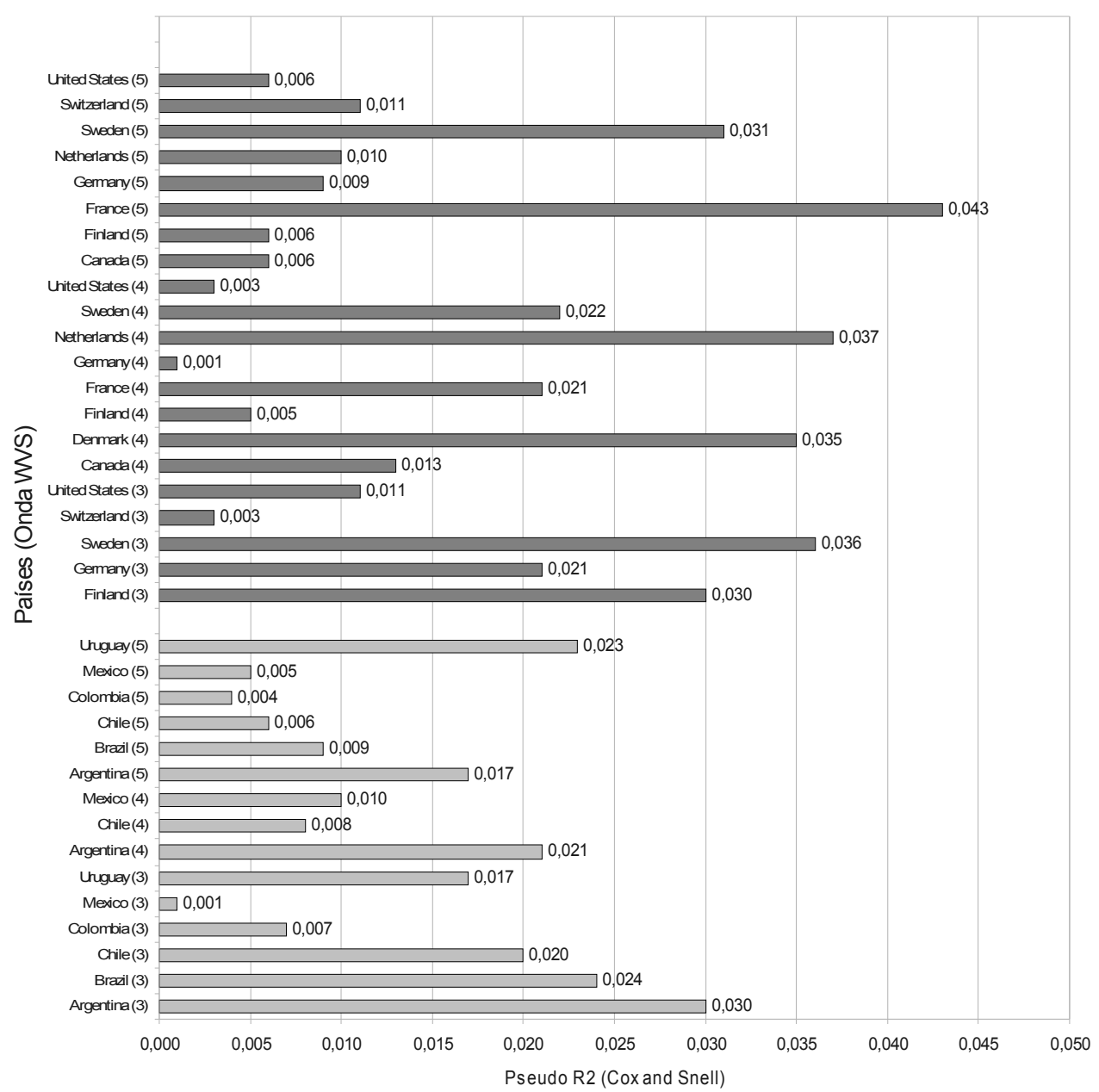

Fonte: World Values Survey, 2006.

Em geral, mesmo levando em consideração o erro-padrão das estimativas, é possível afirmar que existe um padrão de menor grau de influência da relação estudada nas amostras de países latinoamericanos. Contudo, a afirmação de que nesses países essa influência diminui ao longo do tempo requer maior embasamento estatístico além do expresso.

Para evitar de se restringir a questões como o "apoio difuso" à democracia ao considerar "opinião sobre a democracia" como variável 
dependente, foi criado um "índice de participação política"7 com o mesmo objetivo de testar o potencial explicativo do índice pósmaterialista. O mesmo modelo de regressão ordinal foi criado para testar a relação entre as duas variáveis, na quinta onda do WVS, e cujos coeficientes para cada país estão expostos no Gráfico 2.

Gráfico 2 - Regressão Ordinal

(Coeficiente de Cox and Snell)

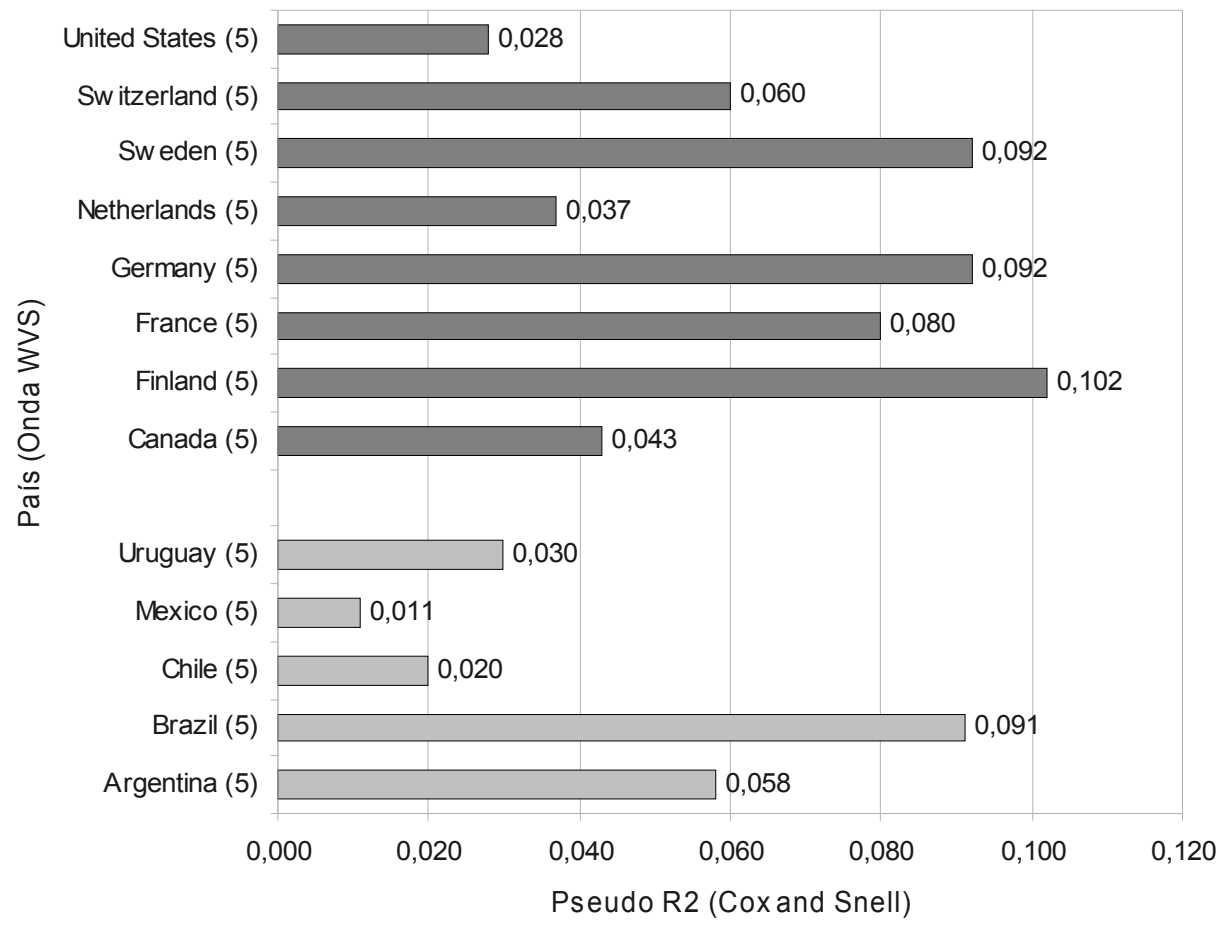

Fonte: World Values Survey, 2006.

Como é possível observar, a participação política dos entrevistados das amostras de países latino-americanos apresenta, geralmente, níveis menores de influência das dimensões mensuradas pelo índice de pós-materialismo quando comparadas a outras sociedades da Europa.

\footnotetext{
${ }^{7} \mathrm{O}$ índice resulta da soma simples das respostas à pergunta se o entrevistado já fez (1), se poderia fazer $(0)$ ou se nunca faria $(-1)$ as seguintes ações políticas: "assinar um abaixo-assinado", "participar de boicotes" e "participar de manifestações pacíficas".
} 
Seligson afirma haver três explicações possíveis para as falhas encontradas por ele em relação ao trabalho de Inglehart:

Primeiro, a teoria geral está errada, o tempo de regime
democrático não tem nada (ou muito pouco) a ver com
a cultura política. Os regimes democráticos podem
surgir e serem sustentados por forças completamente
ausentes dos valores de massa, como os pactos da elite
e os consensos da elite, estrutura de classes, e nível de
desenvolvimento econômico. Segundo, a cultura
política pode ser significativa, mas a variável
selecionada por Inglehart, Putnam e outros pode
estar errada. James L. Gibson verificou,
recentemente, que na Rússia a confiança
interpessoal tem pouca ou nenhuma relevância
para atitudes em relação às instituições ou
processos democráticos. Terceiro, as variáveis
podem estar corretas, mas a sua
operacionalização pode estar equivocada. A
operacionalização do item da confiança
interpessoal, em particular, uma noção altamente
norte-americana, é especialmente suspeita, a
validação internacional de sua mensuração,
desenvolvida em 1957, tem estado virtualmente
esquecida [ausente] (2002, p.287).

Uma reflexão crítica a respeito do conceito de pós-materialismo em Ronald Inglehart, parece iniciar pelo exame das duas últimas explicações levantadas por Mitchel Seligson. Primeiramente, a forma como a cultura política é trabalhada traz diversas dificuldades no que concerne à análise de situações fora de alguns países europeus e norteamericanos, como já foi dito. O conceito de cultura política, as variáveis que o compõem, o escopo formulado e a abordagem proposta demonstraram não se adaptar a outras realidades. Faz-se necessário, portanto, uma reformulação do conceito de cultura política de forma que dê conta dos processos e dinâmicas características da realidade latinoamericana. E, de forma alguma, estes problemas apontam para a ineficácia da análise da cultura política como um aspecto importante para a compreensão de fenômenos políticos - como defendem elitistas e teóricos da escolha racional -, pois como afirma Moisés,

A questão não é tanto de saber se os fatores econômicos ou 'instrumentais' são importantes para a ação política; eles certamente são, mas o fato é que constituem apenas uma parte do fenômeno. Por essa 
razão, sem desconsiderar a importância dos nexos de explicação causal decorrentes dessa contribuição, a dimensão político-cultural - e, associada a ela, a intervenção consciente de elites e não elites no processo político - exerce um papel decisivo na explicação dos comportamentos políticos (1995, p.87).

O que, de fato, aparenta ser inviável é a suposição de que o processo de transformação cultural do materialismo ao pósmaterialismo, observado em alguns países industriais avançados, seja a característica principal e inescapável da cultura política latinoamericana. A atribuição, portanto, de certas características de culturas pós-materialistas como essenciais ao surgimento e estabilidade de regimes democráticos em todo o mundo por meio da operacionalização questionável de determinadas variáveis leva ao que Seligson (2002) chamou de correlação espúria entre atitudes políticas e regimes políticos.

Em suma, visto que estes problemas inviabilizam resultados satisfatórios, se torna inquestionável a necessidade de se desenvolver novos estudos e pesquisas sobre a Cultura Política na América Latina (seus fundamentos, sua constituição, seu papel, sua função nas sociedades latino-americanas e sua relação com a estrutura política) que dêem conta não somente de sua realidade específica, mas que vá além da mera extensão de estudos ou da aplicação de modelos formulados com base em outras realidades sociais, culturais, econômicas e políticas. Ou seja,

um estudo que vise a ir além da aceitação do modelo de cultura cívica deve partir dos conceitos conhecidos, dos trabalhos teóricos e empíricos realizados e dos instrumentos metodológicos disponíveis para procurar construir uma teoria de cultura política adequada às condições da América Latina (CASTRO, 2000, p. 4142).

É esta a conclusão a que tem chegado uma série de estudos a respeito da América Latina (BAQUERO, 1994; CASTRO, 2000; MULLER e SELIGSON, 1994; RENNÓ 2003) e que este trabalho procurou apontar, por meio da revisão da tese do pós-materialismo de Ronald Inglehart, como uma necessidade para os estudos sobre o tema.

REVISTA DEBATES, Porto Alegre, v. 2, n.1, p. 75-97, jan.-jun.2008. 
Henrique Carlos de Oliveira de Castro é doutor em Ciência Política. professor do Centro de Pesquisa e Pós-Graduação sobre as Américas da Universidade de Brasília (CEPPAC/UnB) e pesquisador responsável pela Pesquisa Mundial de Valores no Brasil.

E-mail: henrique@unb.br

Daniel Capistrano é sociólogo e mestrando do Centro de Pesquisa e PósGraduação sobre as Américas da Universidade de Brasília (CEPPAC/UnB). Bolsista da CAPES/MEC.

E-mail: capistrano@unb.br

\section{REFERÊNCIAS:}

ALMOND,G. The Intellectual History of the Civic Culture Concept. In: ALMOND, G.; VERBA, S. The Civic culture revisited. Newbury Park: Sage, 1980. p. 1-32.

ALMOND, G.; VERBA, S. The Civic Culture: Political attitudes and democracy in five nations. Boston: Little, Brown, 1965.

BAQUERO, M. Cultura política e democracia: Os desafios das sociedades contemporâneas. Porto alegre: Ed UFRGS, 1994.

BELL, D. O advento da sociedade pós-industrial. São Paulo: Cultrix, 1973.

CASTRO, H. C. de O. Democracia e mudanças econômicas no Brasil, Argentina e Chile: um estudo comparativo de cultura política. 2000. 172 f. Tese (Doutorado em Ciência Política) - Instituto de Filosofia e Ciências Humanas, Universidade Federal do Rio Grande do Sul, [2000].

CLARKE, $H$. et.al. The effect of economic priorities on the measurement of value change: new experimental evidence. American Political Science Review, Washington D.C., n. 93, v.3, p. 637-47, 1999.

CONRADT, D. Changing German Political Culture. In: ALMOND, G.; VERBA, S. The Civic culture revisited. Newbury Park: Sage, 1980. p. 212-272.

CRAIG, A.; CORNELIUS, W. Political Culture in Mexico: Continuities and Revisionist Interpretations. In: ALMOND, G.; VERBA, S. The Civic culture revisited. Newbury Park: Sage, 1980. p. 325-393.

DAVIS, D.; DAVENPORT, C. Assessing the validity of the Postmaterialism-Index. American Political Science Review, Washington D.C., v. 93, n. 3, p. 649-664, 1999. 
ECKSTEIN, H. A Culturalist Theory of Political Change. In: CROTHERS, L.; LOCKHART, C. Culture and politics: a reader. New York: St. Martin's, 2000. p. 789-804.

HANSEN, O.; TOL, R. A Refined Inglehart Index of Materialism and Postmaterialism. 2003. Disponível em <http://www.unihamburg.de/Wiss/FB/15/Sustainability/inglehart.pdf $>$. Acesso em: 23. mar. 2008.

INGLEHART, R. The Silent Revolution in Europe: Intergenerational Change in Post-Industrial Societies. The American Political Review, v. 65, n. 4, p. 991-1017, 1971.

. Cultural shift in advanced industrial society. New York: Princeton University Press, 1990.

. Modernización y postmodernización: El cambio cultural, económico y político en 43 sociedades. Madrid: CIS/Siglo XXI, 1998.

INGLEHART, R.; BAKER, W. Modernizations Challenge to Traditional Values: Whos Afraid of Ronald McDonald? The Futurist, Maryland, v. 35, n. 2, p. 16-21, mar.-abr. 2001.

MCLARNEY, C.; CHUNG, E. Post-materialism's "silent revolution" in consumer research. Marketing Intelligence \& Planning, v. 17, n. 6, p. 288-297, 1999.

MEDEIROS, M. A Transposição de Teorias sobre a Institucionalização do Welfare State para o Caso dos Países Subdesenvolvidos. Rio de Janeiro: IPEA, 1999.

MOISÉS, J. A. Os brasileiros e a democracia. São Paulo: Ática, 1995.

MULLER, E. N.; SELIGSON, M. A. Civic Culture and Democracy: The Question of Causal Relationships. American Political Science Review, Washington D.C., v. 88, n. 3, p. 635-652, sep. 1994.

RENNÓ, L. R. Revisitando a corrente dominante da teoria da Cultura Política. Revista Brasiliense de Pós-Graduação em Ciências Sociais, Brasília, v. 1, n. 1, p.235-271,1997.

Estruturas de oportunidade política e engajamento em organizações da sociedade civil: um estudo comparado sobre a América Latina. Revista Sociologia Política, Curitiba, n. 21, p. 149-152, nov. 2003.

RIBEIRO, E. A consistência das medidas de pós-materialismo: testando a validade dos índices propostos por R. Inglehart no contexto brasileiro. Revista Sociedade e Estado, Brasília, v. 22, n. 2, p. 371-400, mai.-ago. 2007. 
SELIGSON, M. The Renaissance of Political Culture or the Renaissance of Ecological Fallacy? Comparative Politics, New York, v. 34, p. 273-292, abr. 2002.

TOURAINE, A. A sociedade post-industrial. Lisboa: Moraes Editora, 1970. 